\title{
Therapeutic failure of praziquantel in the treatment of Schistosoma haematobium infection in Brazilians returning from Africa
}

\author{
Iran Mendonça da Silva/ ${ }^{+}$, Roberto Thiengo*, Maria José Conceição**/***, Luis Rey**, \\ Henrique Leonel Lenzi****, Edson Pereira Filho, Paulo César Ribeiro
}

\begin{abstract}
Seção de Vigilância Epidemiológica, Subdivisão de Pesquisa, Divisão de Ensino e Pesquisa, Instituto de Biologia do Exército, Rua Francisco Manuel 102, 20911-270 Rio de Janeiro, RJ, Brasil *Serviço de Urologia, Hospital Central do Exército, Rio de Janeiro, RJ, Brasil **Laboratório de Biologia e Controle de Esquistossomose, Departamento de Medicina Tropical ****Departamento de Patologia, Instituto Oswaldo Cruz-Fiocruz, Rio de Janeiro, RJ, Brasil ***Hospital Universitário Clementino Fraga Filho, Rio de Janeiro, RJ, Brasil
\end{abstract}

Several cases of therapeutic failure of praziquantel used for the treatment of urinary schistosomiasis have been reported. Alternative drugs, like niridazol and metrifonate, have shown a lower therapeutic effect and more side effects than praziquantel. Twenty-six Brazilian military men (median age of 29 years) with a positive urine parasitological exam who were part of a United Nation peace mission in Mozambique in 1994 were treated with $40 \mathrm{mg} /$ $\mathrm{kg}$ body weight praziquantel, single dose. They swimmed in Licungo river (Mocuba city, Mozambique) during the weekends. After this, they presented haematuria, dysuria, polakiuria, and lumbar pain. Control cystoscopy examinations carried out between 6 and 24 months after each treatment (including two additional treatments at a minimum interval of 6 months) revealed the presence of viable eggs. Granulomas in the vesical submucosa were observed in 46.2\% (12/26) of the individuals. A vesical biopsy confirmed the presence of granulomas in all of these patients and the presence of viable eggs in 34.3\% (9/26) of individuals who no longer excreted eggs in urine. The eggs filled with miracidia showed characteristics of viability. Histopathological examination using different strains demonstrated therapeutic failure and the need for repeated treatment. In this study, we demonstrated a low efficacy of praziquantel in the treatment of schistosomiasis haematobia, and the necessity of the urinary bladder biopsy as criterion of cure.

Key words: schistosomiasis therapeutic failure - praziquantel - Schistosoma haematobium - Africa - Brazil

Schistosoma haematobium is present in about 53 African countries and in the Middle East, with the helminth showing high endemicity in these regions (CEGET-CNRSAtlas-WHO/1987, home page-WHO). Urinary schistosomiasis is an infectious disease of marked epidemiological importance for both natives and tourists exposed to the helminth in endemic regions.

Treatment of urinary schistosomiasis has shown great advances with the introduction of praziquantel into the therapeutic arsenal (Bormann et al. 2001, De Clerq et al. 2002). Advantages of this drug include its easy administration $(40 \mathrm{mg} / \mathrm{kg}$ body weight, a single dose by the oral route), low toxicity, and low intensity of side effects (McMahon 1983, Pugh \& Teesdale 1983, Kahama et al. 1999, Rey 2001). These important factors have contributed to the tolerance with and easy application of individualized and mass treatments (Stephenson et al. 1989, King et al. 1992). Nevertheless, failure of praziquantel treatment of various proportions has been reported (Herwaldt et al. 1995, Liang et al. 2000). So, it is necessary to be sure about the

${ }^{+}$Corresponding author. E-mail: silva.iran@ig.com.br Received 21 October 2004

Accepted 29 April 2005 parasitological cure after treatment. Would be possible to have viable eggs in urinary bladder without detection in urine exam? The aim of this study is to evaluate the efficacy of praziquantel in infected individuals who visited endemic areas, and swan in the Licungo river (Mozambique, Africa).

\section{PATIENTS AND METHODS}

Three 24-h urine samples were collected from 26 patients at minimum intervals of one week. The patients were Brazilian military men who were part of the United Nation peace mission in Mozambique in 1994, age between 26 and 55 years old, median age of 29 years. The principal condition was the report of exposure in Licungo river and signals and symptoms affecting the genitourinary tract after exposure.

Helminth eggs were recovered by spontaneous sedimentation and subsequent centrifugation of the urine sample. The total urine volume was transferred to glass chalices and left to stand for $24 \mathrm{~h}$. After this period, $10 \mathrm{ml}$ of the initial sediment was removed with a glass pipette held close to the bottom of the chalice and centrifuged at 3500 r.p.m. for $5 \mathrm{~min}$. One-hundred microliters of the centrifuged material was removed with a glass pipette held close to the bottom of the tube, mounted on a slide, coverslipped, and observed under a microscope at magnifications of $100 \times$ and 400x. For endoscopic examination, an Olympus model $19 \mathrm{CH}$ cystoscope with a $30^{\circ}$ eyepiece was used. 
After the positive diagnosis, the patients were treated with $40 \mathrm{mg} / \mathrm{kg}$ body weight praziquantel administered in a single dose. Three other 24-h urine exams were repeated at 7-day intervals by the same technique, after a minimum period of 21 days after treatment. Treatment was repeated under medical supervision to ensure the correct use of the drug. In the case of suspicion of lesions, all individuals were submitted to cystoscopy followed by biopsy and histopathological examination at 6-month intervals, after each treatment or retreatment, under the same conditions as used for the initial diagnosis. The urine examination, with the same technique, was repeated after each cistoscopy.

In the case of evidence of vesical involvement, a bladder biopsy consisting of two fragments was obtained and processed as follows: the material was immersed in $10 \%$ formalin (dilution of 1 part $40 \%$ formalin in 9 parts of water) and sent to the anatomopathology service which registered the material in alphabetical order of patient's name and order of arrival. The fragments were then analyzed macroscopically and placed in a container called "cassette" labeled with the corresponding registration number. The fragments were again immersed in 10\% formalin and treated in a tissue-processing apparatus. Briefly, the material was dehydrated by 6 washes in absolute alcohol, cleared with xylene, and impregnated and embedded in paraffin while maintaining the identification of the fragments. The specimens were then submitted to passive solidification and the blocks were trimmed and frozen for $30 \mathrm{~min}$. The first fragment was cut into $5-\mu \mathrm{m}$ thick sections with a microtome, while the second fragment was kept en bloc and stored for future exams. The sections were mounted on slides, deparaffinized in an oven at $75^{\circ} \mathrm{C}$ for $20 \mathrm{~min}$, immersed in xylene for removal of the remaining paraffin, and immersed in absolute and 90, 80, and $70 \%$ alcohol for $3 \mathrm{~min}$ each. The fragments were then rehydrated and the slides washed under running water for $15 \mathrm{~min}$, stained with hematoxylin-eosin and analyzed under a microscope at magnifications of $100 \times, 400 \times$ and $1000 x$

Other staining methods (Sirius red, pH 10.2, Alcian blue, $\mathrm{pH} 1.0$ and 2.5, periodic-acid Schiff, Ziehl-Neelsen, and Lennert's Giemsa) were performed at the Department of Pathology, Fiocruz, Rio de Janeiro, to confirm granuloma activity and egg viability.

\section{RESULTS}

Starting 7 days after treatment, all patients became negative to eggs in three samples of 24-h urine exam. The following histopathological alterations were identified in the vesical biopsy material collected during the first cytoscopy (before treatment): edema and chronic inflammation of the chorion, presence of a chronic granulomatous inflammatory process, presence of giant cells in the vesical mucosa, abundant eosinophils, and presence of multinucleated cell granulomas surrounding large amounts of viable S. haematobium eggs (Figs 1,2).

The first control cystoscopy performed 6 months posttreatment with a single dose of $40 \mathrm{mg} / \mathrm{kg}$ praziquantel showed the following results: presence of granulomas in $46.2 \%$ (12/26) of the individuals and absence of granulo-

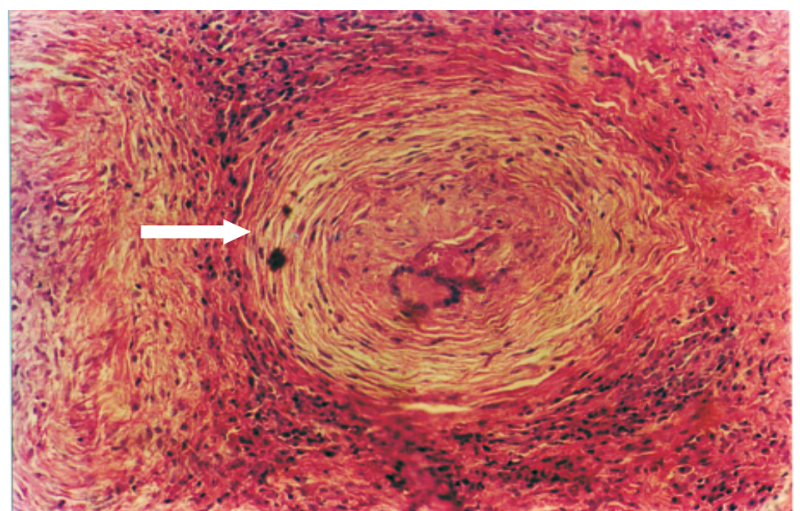

Fig. 1: active granuloma before treatment (white arrow); hematoxylin-eosin staining $100 \times$ magnification

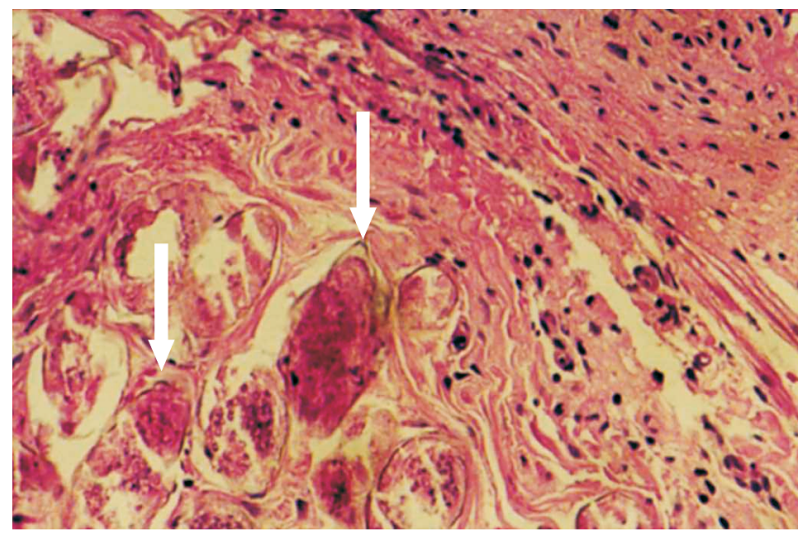

Fig. 2: granuloma and viable eggs before treatment (white arrows); hematoxylin-eosin staining $1000 \times$ magnification

mas in 53.8\% (14/26). Post-treatment histopathological evaluation of the individuals who still presented granulomas upon control cystoscopy revealed the absence of viable eggs in $25 \%$ (3/12) of the individuals, with degenerated granulomas and eggs being observed, and viable eggs in $75 \%(9 / 12)$. The intervals between the treatments and the retreatments ranged from 16 to 30 months, with a mean of 22.8 and a median of 23 months. A second control cystoscopy was performed 12 months after each retreatment under medical supervision in $33.3 \%$ (3/9) of the patients. All patients presented granulomas upon cystoscopy, which were confirmed by histopathological examination demonstrating active granulomas and viable eggs (Figs 3 ,4). The cases presenting viable eggs detected by cystoscopy after treatment were considered to be therapeutic failures and corresponded to $34.6 \%(9 / 26)$ of the individuals treated and reassessed. Sirius red, Alcian blue, periodic-acid Schiff, Ziehl-Neelsen and Lennert's Giemsa staining confirmed the viability of the eggs which were characterized by mast cells on the egg surface, nervous system cells, germinative cells, pyknotic cells around the nervous system, and viable eggs containing proteoglycans. Granulomas in the exudative-productive phase were also observed. The remaining patients $(65.4 \%, 17 / 26)$ were considered to be cured. 


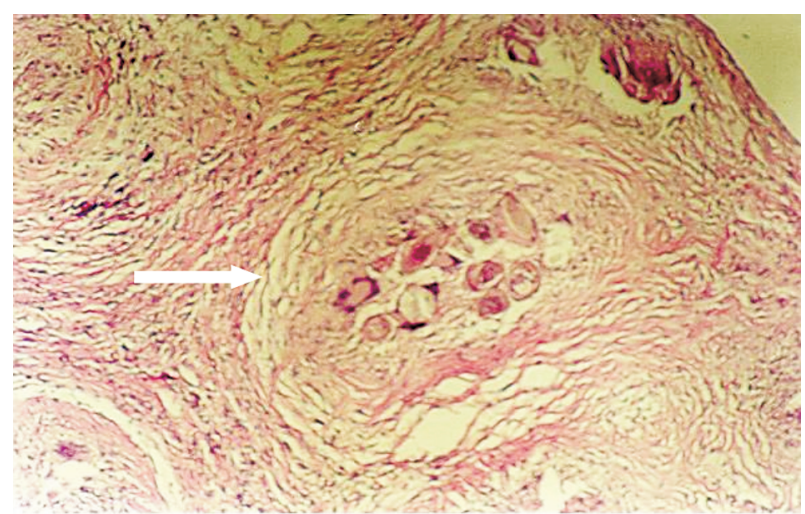

Fig. 3: active granuloma and eggs after treatment (white arrow), hematoxylin-eosin staining $100 \times$ magnification

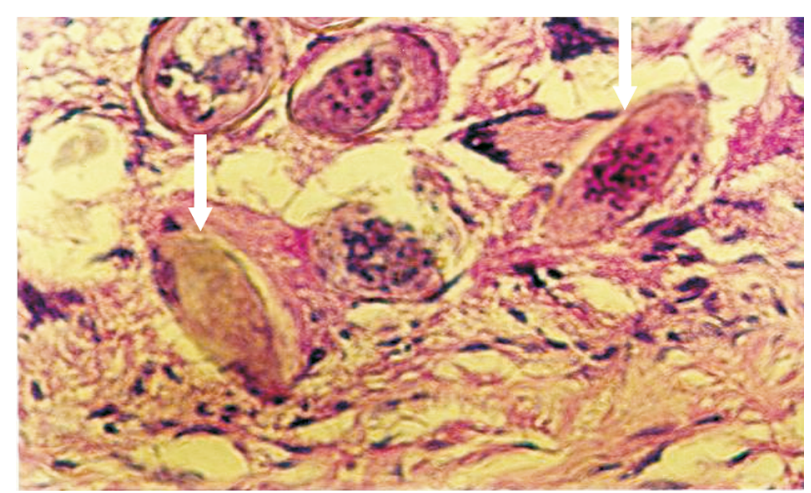

Fig. 4: viable eggs after treatment (white arrows), hematoxylineosin staining $1000 \times$ magnification

\section{DISCUSSION}

Although praziquantel is the drug of choice for the treatment of $S$. haematobium infections (Gentilini et al. 1982, McMahon 1983, Pugh \& Teesdale 1984, Stephenson et al. 1989, McNeeley et al. 1990, King et al. 1992, King \& Mahmoud 1999, King et al. 2002), cases of treatment failure have been frequently reported, probably due to a progressive increase in the resistance of the parasite to the drug, as observed by some authors (Groning et al. 1985, Herwaldt et al. 1995, Hatz et al. 1998, Ernould et al. 1999, Liang et al. 2000). Despite the controversies regarding the rapid emergence of praziquantel resistance, constant surveillance of this progression is important. Criteria of cure based on the absence of egg elimination in urine have shown a variation of 60 to $96 \%$ (Pugh \& Teedasle 1983, Wilkins \& Moore 1987, Kahama et al. 1999) in endemic areas, with the existence of rare cases of $100 \%$ parasitological cure (Saliba et al. 1997), depending on the intensity of infection.

Post-treatment follow-up is generally performed by noninvasive methods such as ultrasound of the urinary tract, which, however, do not identify treatment failure (Hatz et al. 1998, Wagatsuma et al. 1999). Although studies have reported the persistence of pathological alterations and even the development of complications identified by ultrasound in treated patients, no histopathologi- cal evidence exists regarding the persistence of viable eggs after long post-treatment periods. Frequently, fibrosis regresses after treatment and interruption of exposure, although pathological manifestations may persist for a long period (Delegue et al. 1998, Richter 2000, King et al. 2002).

Repeated negative urine exams are not absolute criteria of parasitological cure. In the present patients, viable eggs in the process of extrusion were observed in the vesical mucosa, with elimination possibly occurring with time. In these cases, the presence of eggs in urine is only an occasional finding. In endemic areas, criteria of cure are probably difficult to establish (Mduluza et al. 2001) because it is difficult to determine whether the elimination of eggs after successive treatments with praziquantel is caused by reinfection or by therapeutic failure. The criterion of repeated urine evaluation after treatment seems to be more useful for the diagnosis of persistent excretion of eggs in urine and fulfills the objectives of the control of transmission. However, cystoscopy in combination with biopsy and histopathological evaluation might be a better criterion of cure, especially in the case of chronic infection of travelers.

Histopathological examination is a highly sensitive method for the identification and follow-up of the evolution of schistosomiasis, specially in chronic cases without re-exposure, a situation in which the elimination of eggs is precarious and complications also occur.

In the present study, granulomas in the exudative, exudative-productive, and involutional phase were observed. Individuals with viable eggs presented granulomas in the first two phases and a new biopsy was obtained after treatment (praziquantel $40 \mathrm{mg} / \mathrm{kg}$ body weight, single dose) in these cases. The patients were treated again under medical supervision to ensure the correct ingestion of the drug (with the same dose). A new assessment performed 6 to 24 months post-treatment still showed the presence of viable eggs and granulomas in the productive phase. During post-treatment evolution, granulomas in the involutional phase, containing degenerated or degenerating eggs, were generally observed. Histopathologically, $34.6 \%(9 / 26)$ of the treated patients had active and chronic infection, while the remaining patients $(65.4 \%)$ presented degenerated eggs, granulomas in the involutional phase or no histopathological alterations.

The specimens were submitted to other staining methods performed at the Department of Pathology, Fiocruz, Rio de Janeiro, to confirm granuloma activity and egg viability. The results confirmed the characteristics of egg viability such as mast cells on the egg surface, nervous system cells, germinative cells, pyknotic cells around the nervous system, and viable eggs containing proteoglycans. Granulomas in the exudative-productive phase were also observed. No eggs were detected in the three 24-h urine samples obtained from patients at one-week intervals and after 21 days of treatment or retreatment. The presence of viable eggs in the process of excretion in the vesical wall during chronic evolution and after treatment indicates the migration and elimination of these eggs with time; thus, the absence of eggs in urine might be temporary in this situation. In view of the findings of therapeu- 
tic failure, the need for alternative drugs becomes evident (McMahon 1983, Tswana \& Mason 1985, Wilkins \& Moore 1987, McNeeley et al. 1990, Lambertucci 1995, Ernould et al. 1999, Utzinger et al. 2001). One alternative drug, niridazole, has not been frequently reported in the literature. Metrifonate is other alternative drug, but it is used in 3 doses ( 7 days intervals), the efficacy is lower than praziquantel and it is not commercialized in Brazil. The major advantage of metrifonate in the past has been its low cost of production. With the lowering costs of praziquantel, the cost differential is now negligible. This has led to discontinuation of drug distribution in several endemic countries (Olds \& Dasarathy 2000).

The preferential use of praziquantel and the important side effects of niridazole and metrifonate favor the first as the drug of choice for the treatment of schistosomiasis. Some experimental studies on artesunate administered alone or in combination with praziquantel have been reported, but no recommendations regarding its use exist and investigations have demonstrated the superiority of praziquantel in terms of the therapeutic response (Bormann et al. 2001, De Crerq et al. 2002).

Praziquantel should continue to be the drug of choice for the treatment of schistosomiasis due to its lower toxicity and higher rate of compliance with the recommended dose. However, criteria of cure should be taken into account in order to avoid the attribution of an equivocal efficacy to this drug, especially in chronic cases in which cystoscopy followed by biopsy of the suspected lesions and subsequent histopathological evaluation seems to be a more sensitive method. The elimination of parasite eggs is precarious in chronic cases without reinfection and the process tends to continue, with all the pertinent complications. The criterion of cure should be established on the basis of the absence of alterations in the vesical mucosa and, in the case of mucosal changes, biopsy and histopathological examination should be performed to identify lesion activity and the presence of viable eggs.

Actually, we are controlling the evolution and complications in 9 patients. The complications were one-sided ureteral stenosis (just one), pyelocalix dilatation and urinary lithiasis. We verified therapeutic failure with single dose of $40 \mathrm{mg} / \mathrm{kg}$ weight praziquantel in 9 patients, since that the first aim of treatment is the parasitological cure with single dose. After retreament with 3 doses of praziquantel (15 days intervals), we are evaluating again and we have 4 patients with normal cystoscopy (6 months post-retreatment).

Maybe, in the future, in areas with low efficacy of praziquantel, the dose will be increased or repeated.

\section{ACKNOWLEDGMENTS}

To the Serviço de Anatomopatologia, Hospital Central do Exército, Rio de Janeiro, for technical support.

\section{REFERENCES}

Bormann S, Nicles S, Faucher JF, Matsiegui PB, Neubauer R, Binder RK, Lell B, Kremsner PG 2001. Artesunate and praziquantel for treatment of Schistosoma haematobium infections: a double-blind, randomized, placebo-controlled study. J Infect Dis 184: 1363-1366.
CEGET-CNRS/OMS-WHO 1987. Atlas of the Global Distribution of Schistosomiasis 28, p. 223-230.

De Clercq D, Vercruysse J, Kongs A, Verde P, Dompnier JP, Faye PC 2002. Efficacy of artesunate and praziquantel in Schistosoma haematobium infected schoolchildren. Acta Trop 82: 61-66.

Delegue P, Picquet M, Shaw DJ, Vercruysse J, Sambou B, Ly A 1998. Morbity induced by Schistosoma haematobium infections, as assessed by ultrasound before and after treatment with praziquantel, in a recently expanded focus (Senegal River basin). An Trop Med Parasitol 92: 775-783.

Ernould JC, Ba K, Sellin B 1999. Increase of intestinal schistosomiasis after praziquantel treatment in Schistosoma haematobium and Schistosoma mansoni mixed focus. Acta Trop 73: 143-152.

Gentilini M, Brucker G, Danis M, Mogahed A \& Datry A 1982. Traitment de la bilharziose urinaire et intestinale par praziquantel. Bul Soc Path Exot 75: 523-529.

Groning E, Bakathir H, Salem A, Albert L, Fernández R 1985. Efectividade y tolerancia de praziquantel. Rev Cub Med Trop 37: 215-219.

Hatz CF, Vennervald BJ, Nkulila T, Vounatsou P, Kombe Y, Mayombana C, Mshinda H, Tanner M 1998. Evolution of Schistosoma haematobium - related pathology over 24 months after treatment with praziquantel among school children in southeastern Tanzania. Am J Trop Med Hyg 59: 775-781.

Herwaldt BL, Tao L, Van Pelt W, Tsang VC, Bruce JI 1995. Persistence of Schistosoma haematobium infection despite multiple courses of therapy with praziquantel. Clin Infect Dis 20: 309-315.

Home Page - World Health Organization. htpp://www.who.int/ ctd/schisto/burdens.htm.

Kahama AI, Vennervald BJ, Kombe Y, Kihara RW, Ndzoru M, Mungai P, Ouma JH 1999. Parameters associated with Schistosoma haematobium infection before and after chemoterapy in school children from two villages in the Coast province of Kenya. Trop Med Int Health 4: 335-340.

King CH, Mahmoud AAF 1999. Drugs five years later: praziquantel. Ann Inter Med 110: 290-296.

King CH, Muchiri EM, Ouma JH 1992. Age-targeted chemotherapy for control of urinary schistosomiasis in endemic populations. Mem Inst Oswaldo Cruz 87: 203-210.

King CH, Muchiri EM, Ouma JH, Kadzo H, Magak P, Koech DK 2002. Randomized comparison of low-dose versus standard-dose praziquantel therapy in treatment of urinary tract morbidity due to Schistosoma haematobium infection. Am J Trop Med Hyg 66: 725-730.

Lambertucci JR 1995. Treatment of schistosomiasis: gathering stones together. Mem Inst Oswaldo Cruz 90: 161-164.

Liang YS, Coles GC, Doenhoff MJ 2000. Short communication: Detection of praziquantel resistance in schistosomiasis. Trop Med Int Health 5: 72.

Mcmahon JE 1983. A comparative trial of praziquantel, metrifonate and niridazole against Schistosoma haematobium. Ann Trop Med Parasitol 77: 139-142.

Mcneeley DF, Habbib MA, Morgan SH, Azziz FA, Cline BL 
1990. Changes in a antischistosomal drug usage patterns in rural Qalyubia - Egypt. Am J Trop Med Hyg 42: 157-159.

Mduluza T, Ndhlovu PD, Madziwa TM, Midzi N, Zinyama R, Turner CMR, Chandiwama SK, Nyazema N, Hagan P 2001. The impact of repeated treatment with praziquantel of schistosomiasis in children under six year of age living in an endemic area for Schistosoma haematobium infection. Mem Inst Oswaldo Cruz 96: 157-164.

Olds GR, Dasarathy S 2000. Schistosomiasis. Cur Treat Options in Infect Dis 2: 88-99.

Pugh RNN, Teesdale CH 1983. Single dose treatment in urinary schistosomiasis: a double blind trial. $\mathrm{Br}$ Med J 286: 429432.

Pugh RNN, Teesdale CH 1984. Long-term efficacy of singledose oral treatment in schistosomiasis haematobium. Trans $R$ Soc Trop Med Hyg 78: 55-59.

Rey L 2001. Schistosoma haematobium e esquistossomíases. In Parasitologia Médica, $3^{\mathrm{a}}$ ed., Atheneu, São Paulo, p. 444-454.

Richter J 2000. Evolution of schistosomiasis-induced pathology after therapy and interruption of exposure to schistosomes: a review of ultrasonography studies. Acta Trop 77: $111-131$.
Saliba EK, Tawfiq MR, Kharabsheh S, Rahameh J 1997. Urinary schistosomiasis contracted from na irrigation pool in Ramah, the southern Jordan Valley, Jordan. Am J Trop Med Hyg 57: 158-161.

Stephenson LS, Latham MC, Kurz KM, Kinoti SN 1989. Single dose metrifonate or praziquantel treatment in kenian children. II. Effects on growth in relation to Schistosoma haematobium and hookworm egg counts. Am J Trop Med Hyg 4: 445-453.

Tswana SA, Mason PR 1985. Eighteen-month follow-up on the treatment of urinary schistosomiasis with a single dose of metrifonate. Am J Trop Med Hyg 34: 746-749.

Utzinger J, Shuhua X, N'goran EK, Bergquist R, Tanner M 2001. The potential of artemether for the control of schistosomiasis. Int J Parasitol 31: 1549-1562.

Wagatsuma Y, Aryeetey ME, Sack DA, Morrow RH, Kojima S 1999. Resolution and resurgence of Schistosoma haematobium induced pathology after community-based chemotherapy in Ghana, as detected by ultrasound. J Infect Dis 179: 1515-1522.

Wilkins HA, Moore PJ 1987. Comparative trials of regimes for the treatment of urinary schistosomiasis in the Gambia. Am J Trop Med Hyg 90: 83-92. 
